\title{
Aerodynamic Roughness Length of Fresh Snow
}

\author{
Christof Gromke · Costantino Manes • \\ Benjamin Walter • Michael Lehning • Michele Guala
}

Received: 7 December 2010 / Accepted: 11 May 2011 / Published online: 3 June 2011

(C) Springer Science+Business Media B.V. 2011

\begin{abstract}
This study presents the results from a series of wind-tunnel experiments designed to investigate the aerodynamic roughness length $z_{0}$ of fresh snow under no-drift conditions. A two-component hot-film anemometer was employed to obtain vertical profiles of velocity statistics in a zero pressure gradient turbulent boundary layer for flow over naturally deposited snow surfaces. The roughness of these snow surfaces was measured by means of digital photography to capture characteristic length scales that can be related to $z_{0}$. Our results show that, under aerodynamically rough conditions, the mean value of the roughness length for fresh snow is $\left\langle z_{0}\right\rangle=0.24 \mathrm{~mm}$ with a standard deviation $\sigma\left(z_{0}\right)=0.05 \mathrm{~mm}$. In this study, we show that variations in $z_{0}$ are associated with variations in the roughness geometry. The roughness measurements suggest that the estimated values of $z_{0}$ are consistent with the presence of irregular roughness structures that develop during snowfalls that mimic ballistic deposition processes.
\end{abstract}

Keywords Aerodynamic roughness length · Hot-film anemometry ·

Rough-wall turbulent boundary layer $\cdot$ Snow $\cdot$ Surface roughness $\cdot$ Wind tunnel

\section{Introduction}

The aerodynamic roughness length $z_{0}$ is a key parameter for micrometeorological applications because it determines the efficiency of momentum and scalar transport occurring between land and atmosphere and because it influences the mean and turbulent flow structure

C. Gromke $(\bowtie) \cdot$ B. Walter $\cdot$ M. Lehning

WSL Institute for Snow and Avalanche Research SLF, Flueelastr. 11, 7260 Davos, Switzerland

e-mail: gromke@slf.ch

C. Manes

Dipartimento di Idraulica, Trasporti e Infrastrutture Civili, Politecnico di Torino, Torino, Italy

M. Guala

Saint Anthony Falls Laboratories, University of Minnesota, Minneapolis, MN, USA 
of the surface layer. In fluid mechanics $z_{0}$ has been estimated for a variety of roughness types by means of numerical (e.g. Orlandi and Leonardi 2008) and laboratory experiments (e.g. Nikuradse 1933; Raupach et al. 1991). In contrast, the aerodynamic roughness length of snow-covered surfaces has been estimated only in field studies that obviously cannot provide the same level of accuracy as laboratory experiments. Therefore, the uncertainty around the values of $z_{0}$ for snow-covered surfaces is very high. Even for homogeneous flat terrain without large surface features, such as sastrugi or ripples, the reported $z_{0}$ for snow spans a range of two orders of magnitude (Poggi 1977; Bintanja and Van den Broeke 1995; Andreas et al. 2005). One reason for such a large uncertainty is that, at most field stations, wind speeds were measured only at a few height levels. The profile analysis thus relies on a very limited number of vertical points and bears much statistical uncertainty. Moreover, as anemometers in field studies are usually not placed close enough to the ground to capture the region of the highest velocity gradient, the exact determination of the aerodynamic roughness length is further complicated. Also, the common deployment of mechanical wind sensors, e.g. cup or propeller anemometers, which are subject to overspeeding in gusty winds, leads inherently to errors in the estimation of $z_{0}$ (Kaimal and Finnigan 1994; Foken 2008). In addition, the analysis is complicated by the mobile nature of snow surfaces. The datum level, referred to as the mean elevation of the surface, may change within a couple of minutes before and after snow-drift events. The non-stationary nature of atmospheric flows and thermal effects represent further sources of uncertainty. Drifting snow itself may act to change the roughness length analogous to Charnock's relation for wavy water surfaces (Charnock 1955), and then extended to the case of saltating particles, $z_{0 \mathrm{~s}}=c u_{*}^{2} / g$ with $c \approx 0.1-0.2$ (Chamberlain 1983; Owen 1964; Pomeroy and Gray 1990; Raupach 1991; Doorschot et al. 2001; Calanca 2001). It is noted, however, that recent results from Andreas et al. (2010) suggest that the roughness length does not depend on the friction velocity in the drifting snow regime.

In general, snow-covered surfaces show a wide range of roughness scales that can arise from the deposition processes of snow crystals, non-uniform melting processes, larger scale roughness elements (ripples, sastrugi or other erosion and deposition features resulting from wind erosion) and topography. The latter two are especially relevant for the aerodynamic roughness length as $z_{0}$ is strongly determined by the largest surface elements. It is also noteworthy that $z_{0}$ may change considerably over time at a specific site as those features evolve or disappear during wind erosion events (Andreas and Claffey 1995).

For flat Antarctic terrain covered with sastrugi, Jackson and Carroll (1978) measured roughness lengths in the range of $z_{0}=0.01-70 \mathrm{~mm}$, and found $z_{0}$ to strongly depend on the angle of the approaching wind direction and the main sastrugi axis. For aligned winds, the smallest $z_{0}$ values were measured. With increasing angle, increasing $z_{0}$ were observed, showing a maximum of $\approx 70 \mathrm{~mm}$ at $60-80^{\circ}$. Inoue (1989) reports even smaller values for the aerodynamic roughness length over sastrugi covered surfaces of the range $z_{0}=0.001-$ $1 \mathrm{~mm}$. In contrast to Jackson and Carroll (1978), he could not identify a clear correlation between the magnitude of $z_{0}$ and the angle of approaching wind, and the sastrugi orientation. However, it has to be critically annotated that the data of both the studies underlie the various sources of errors and uncertainties of field site measurements as mentioned above.

In this article, we focus on the aerodynamic roughness length of fresh snow on flat surfaces in the absence of drift, which is influenced by roughness scales, the dimensions of which are dictated solely by the deposition process of crystals (or flakes) during a snowfall (Lowe et al. 2007; Manes et al. 2008), while we are aware that in real environments the roughness length is often determined by terrain (Doorschot et al. 2004), or by larger scale snow features (Herzfeld et al. 2003; Leonard 2009). The incentive for the study arose from the fact that $z_{0}$ of fresh snow represents an important boundary and initial condition for numerical models 
simulating snow-atmosphere interaction and snowpack evolution (Lehning and Fierz 2008; Lehning et al. 2008; Manes et al. 2008; Stoessel et al. 2010).

The main objective, therefore, is to provide a robust estimate of the aerodynamic roughness length $z_{0}$ of flat fresh snow surfaces using well-controlled flow conditions (a zero pressure gradient boundary layer as obtained in a wind tunnel). This estimate is substantiated by a full set of mean velocity and turbulence statistics along with geometrical roughness measurements and a functional relationship between the aerodynamic and geometrical roughness scales. To this end, experiments were performed at the WSL Institute for Snow and Avalanche Research SLF cold wind tunnel, which is a unique facility capable of hosting naturally deposited snow surfaces. The main advantage of our experimental set-up, as compared with field measurements, is that in the cold wind tunnel, we could recreate similar surface conditions to those observed in the field without suffering from the uncertainty and unsteadiness effects associated with atmospheric flow. The set-up is well suited for the investigation of homogeneous and flat snow surfaces. However, we are restricted to neutral stratification and surface features related to the snow deposition process. Larger roughness scales that may generate and evolve due to wind erosion (sastrugi, ripples, erosion troughs, deposits) and their effects on the aerodynamic roughness length cannot be studied.

The article is organized as follows: in Sect. 2, we briefly describe the experimental facility and the technical procedures employed to obtain flow and surface roughness measurements. In Sect. 3, we present turbulent boundary-layer statistics. The estimates of the aerodynamic roughness length together with the available literature data are presented in Sect. 4, and the relationship between $z_{0}$ and geometrical roughness scales is discussed in Sect. 5. Conclusions are presented in Sect. 6 .

\section{Methods}

\subsection{Boundary-Layer Wind Tunnel, Experimental Set-up and Procedure}

The experiments have been performed in the boundary-layer wind tunnel at the WSL Institute for Snow and Avalanche Research SLF in Davos/Switzerland. The wind tunnel is housed in a non-heated building at $1650 \mathrm{~m}$ a.s.l and operated with fresh outdoor air. This facility has been used in the past to investigate snow-atmosphere interaction processes such as drifting snow (Clifton et al. 2006; Guala et al. 2008; Clifton and Lehning 2008) or shear-induced snowpack ventilation (Clifton et al. 2008; Bartlett and Lehning 2011). The wind tunnel is an open-circuit suck-down type. Its total length is $17 \mathrm{~m}$, with a cross-section of $1 \mathrm{~m} \times 1 \mathrm{~m}$ (Fig. 1), and an adjustable ceiling allows for the control of the streamwise pressure gradient.

For the experiments, an 8-m-long snow fetch was set-up in the test section of the wind tunnel; the fetch was realized by four custom-made trays of 2-m length and 1-m width (Fig. 2). These trays were placed outside the building in a wind-sheltered and sun-shaded area so that, during a snowfall, they were filled with naturally deposited snow. When sufficient snow was collected, the trays were carefully brought into the building and positioned into the windtunnel test section. The snow surface was then flush levelled to the upwind wooden floor by means of a set of lifting tables, which allowed for an optimal vertical positioning of the test section. This procedure allowed boundary-layer experiments to be performed with an undisturbed, flat, naturally deposited fresh snow surface. It should be noted that the term 'fresh snow surface' in the context of this study refers to flat snowpacks characterized by roughness features resulting solely from the deposition of snow crystals/flakes occurring during a snowfall (Manes et al. 2008). This implies that in order to perform any experiment, snowfall 


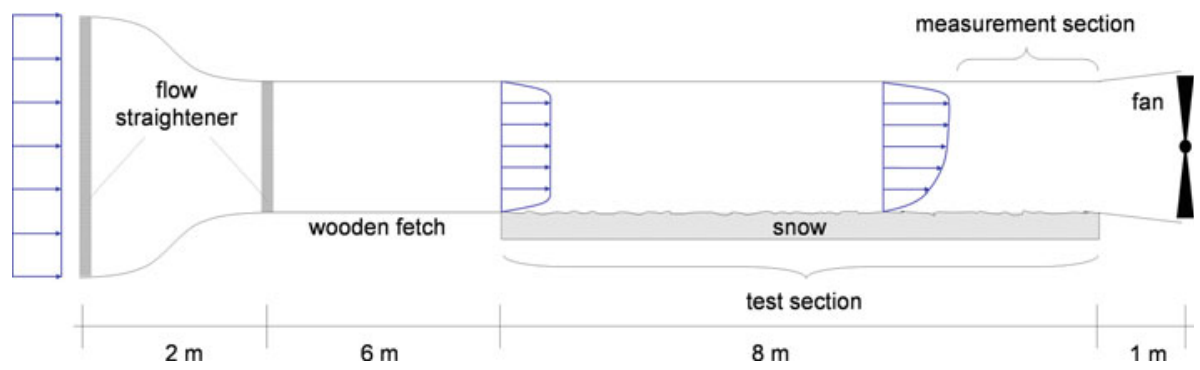

Fig. 1 Atmospheric boundary-layer wind tunnel at the WSL Institute for Snow and Avalanche Research SLF

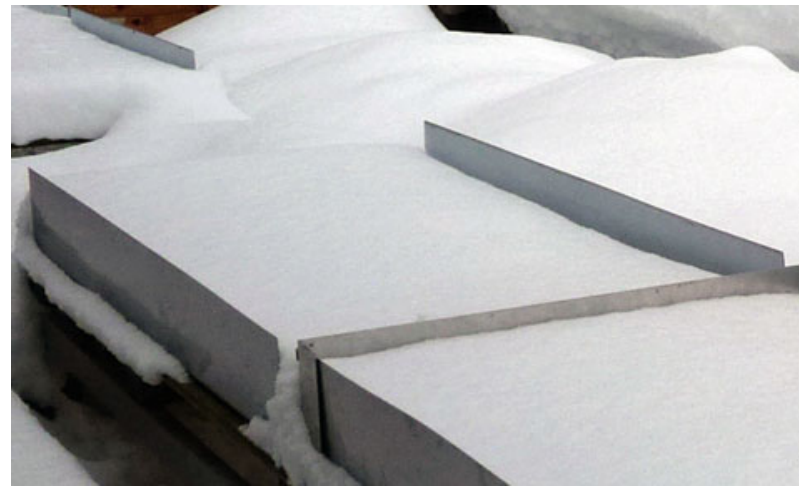

Fig. 2 Snow tray with a naturally deposited snowpack outside the wind-tunnel building

had to occur in the absence of strong winds and at temperatures lower than $0{ }^{\circ} \mathrm{C}$, to avoid the formation of roughness features resulting from snow drift and melting, respectively.

In the three winter seasons of the period from December 2007 to March 2010, these weather conditions were respected for seven snowfalls, and ten experiments were performed for seven different snow surfaces (in two cases the same surface was used for different Reynolds numbers as specified in Table 1). Before each experiment, the wind-tunnel ceiling was adjusted to reach a zero streamwise pressure gradient, which was monitored by means of pressure taps placed along the whole wind-tunnel length with a longitudinal spacing of $0.5 \mathrm{~m}$. For each experiment, the flow velocities were kept below the onset of snowdrift to ensure that the snow-surface roughness remained close to the initial condition. It is noted that the duration of the experiments was kept short enough $(\approx 1 \mathrm{~h})$ so that the effects of metamorphism on the snow roughness could be considered small (Pinzer and Schneebeli 2009). A smooth-wall experiment was performed to check the reliability of the wind-tunnel configuration and also to provide a reference for data comparison with the snow experiment. The details of the experimental conditions for all the experiments are reported in Table 1.

\subsection{Velocity Measurement Technique}

Constant temperature anemometry (CTA: model Dantec Dynamics StreamLine) was applied to measure flow velocities. A two-dimensional platinum coated hot-film X probe (model TSI 1241-60) with $3.05 \mathrm{~mm}$ wire spacing and $2.03 \mathrm{~mm}$ sensing area length was employed to determine vertical profiles of the streamwise and wall-normal velocity components $u^{\prime}$ and 
Table 1 Boundary-layer flow parameters

\begin{tabular}{llllllll}
\hline $\begin{array}{l}\operatorname{Re}_{\theta} \\
(-)\end{array}$ & $\begin{array}{l}U_{\delta} \\
\left(\mathrm{m} \mathrm{s}^{-1}\right)\end{array}$ & $\begin{array}{l}u_{*} \\
\left(\mathrm{~m} \mathrm{~s}^{-1}\right)\end{array}$ & $\begin{array}{l}\delta \\
(\mathrm{m})\end{array}$ & $\begin{array}{l}z_{0} \\
(\mathrm{~mm})\end{array}$ & $\begin{array}{l}T \\
\left({ }^{\circ} \mathrm{C}\right)\end{array}$ & $\begin{array}{l}v \\
\left(\mathrm{~m}^{2} \mathrm{~s}^{-1}\right)\end{array}$ & $\begin{array}{l}z_{0}^{+} \\
(-)\end{array}$ \\
\hline 9800 & 4.43 & 0.19 & 0.30 & 0.25 & -6.5 & $1.59 \mathrm{e}-5$ & 3.0 \\
$10200^{\mathrm{a}}$ & 5.10 & 0.22 & 0.30 & 0.23 & -2.3 & $1.65 \mathrm{e}-5$ & 3.1 \\
10300 & 5.45 & 0.23 & 0.25 & 0.17 & -3.8 & $1.60 \mathrm{e}-5$ & 2.5 \\
11900 & 5.51 & 0.23 & 0.29 & 0.19 & -2.0 & $1.65 \mathrm{e}-5$ & 2.7 \\
12500 & 5.50 & 0.26 & 0.29 & 0.33 & -1.7 & $1.63 \mathrm{e}-5$ & 5.3 \\
13300 & 5.49 & 0.23 & 0.30 & 0.27 & -1.7 & $1.67 \mathrm{e}-5$ & 3.8 \\
$19500^{\mathrm{b}}$ & 8.37 & 0.34 & 0.29 & 0.20 & -1.2 & $1.65 \mathrm{e}-5$ & 4.1 \\
$22400^{\mathrm{a}}$ & 8.45 & 0.35 & 0.29 & 0.27 & -2.2 & $1.65 \mathrm{e}-5$ & 5.7 \\
$24600^{\mathrm{b}}$ & 10.75 & 0.44 & 0.30 & 0.19 & -1.2 & $1.65 \mathrm{e}-5$ & 5.1 \\
$26300^{\mathrm{a}}$ & 10.70 & 0.45 & 0.29 & 0.25 & -2.1 & $1.65 \mathrm{e}-5$ & 6.9 \\
24600 (smooth) & 14.00 & 0.42 & 0.28 & 0.005 & 2.8 & $1.60 \mathrm{e}-5$ & 0.1 \\
\hline
\end{tabular}

$\mathrm{a}, \mathrm{b}$ Indicate the same snow surfaces

$w^{\prime}$, respectively. Although a better spatio-temporal resolution could have been achieved using probes with smaller wires and thus a smaller measurement volume, the TSI 1241-60 probe was chosen to resist possible impacts caused by moving snow particles. The calibration of the CTA/hot-film system was done in situ immediately before each experiment against a certified miniature fan anemometer (model Schiltknecht MiniAir20) in the free stream. Velocity time series of $60 \mathrm{~s}$ length were recorded for each measurement point with a sampling frequency of $f_{\mathrm{s}}=20,000 \mathrm{~Hz}$. The integral time scale in the flows investigated was a posteriori found to be in the order of $0.05 \mathrm{~s}$ throughout the entire boundary layer. In addition, assuming the largest scales of the flow in the order of $10 \delta$ (e.g. Guala et al. 2006, 2011), with $\delta=O\left(10^{-1}\right) \mathrm{m}$ and the free stream velocity $U_{\delta}=O(10) \mathrm{m} \mathrm{s}^{-1}$, we obtain a time scale of approximately $0.1 \mathrm{~s}$. Each 60 -s record can be thus considered as an ensemble average of $\approx 600-1200$ large-scale turnover times, thus ensuring robust velocity statistics.

\subsection{Geometrical Snow-Surface Roughness Characterization}

A detailed description of the procedure employed to measure and characterize snow roughness can be found in Manes et al. (2008). However, for the sake of clarity, a brief summary is reported in the following. Before each wind-tunnel experiment, snow-surface photographs were taken and processed by digital image analysis to obtain the contour line of the snow-air interface. For this purpose, a ruler with a sharp-edged black painted blade was carefully inserted into the snowpack without destroying its natural surface structure (Fig. 3). The pictures of the snow-air interface were then taken with a high-resolution digital camera (Canon PowerShot Pro 1, 8.0-megapixel resolution). The contrast between the white snow and the dark target allowed the roughness outlines to be easily captured.

The snow-roughness elevations were then employed to compute the second-order structure functions defined as

$$
D_{2}(r)=\left\langle[z(x+r)-z(x)]^{2}\right\rangle,
$$

where $r$ is the spatial lag and the angle brackets denote ensemble averaging over different $x$. Manes et al. (2008) recognized that a few characteristic spatial lags separating different 

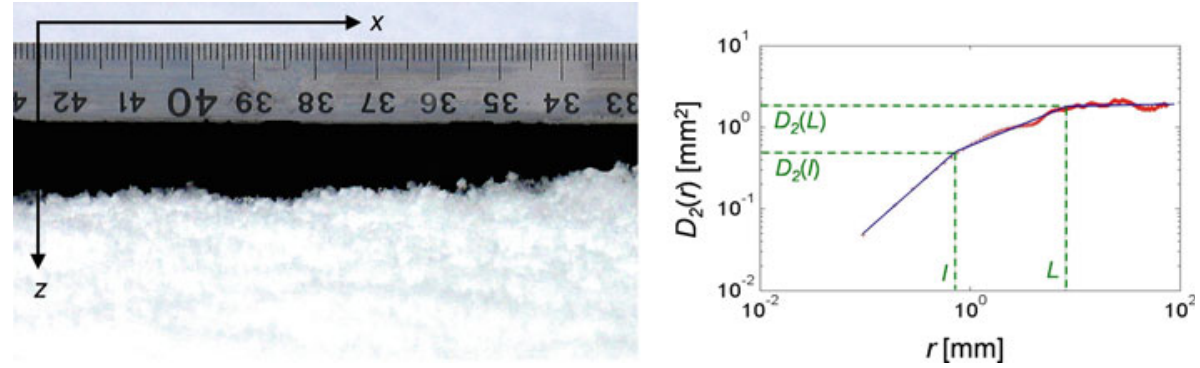

Fig. 3 Snow-air interface contour line and characteristic length scales for the second-order structure function $D_{2}(r)$

scaling regions in $D_{2}(r)$ identify key length scales of the snow roughness. These are the crossover length $l$, the saturation length $L$ and their corresponding vertical length scales, i.e. $\sigma_{l}=\left[D_{2}(l) / 2\right]^{1 / 2}$ and $\sigma_{L}=\left[D_{2}(L) / 2\right]^{1 / 2}=k_{\text {rms }}$ (Fig. 3). They found that $l$ and $\sigma_{l}$ can be interpreted as characteristic horizontal and vertical length scales of snow crystals, whereas $L$ and $\sigma_{L}$ are associated with the typical horizontal and vertical length scales of roughness structures emerging when the snowfall mimics a ballistic deposition process, respectively (Barabási and Stanley 1995). Analysis of the second-order structure functions revealed that such structures are present in all the snow surfaces investigated in this study, and their scaling behaviour is indeed consistent with that of ballistic deposition processes as discussed in Manes et al. (2008).

\subsection{Determination of Logarithmic Profile Parameters}

The hot-film X probe was traversed along a vertical line in the measurement section close to the end of the snow fetch (Fig. 1) to acquire time series of the streamwise and wall-normal flow velocities $u(t)$ and $w(t)$, respectively. According to the turbulent boundary-layer theory, in the constant shear-stress layer (i.e. where $\left\langle u^{\prime} w^{\prime}\right\rangle=$ constant) mean flow velocities $U(z)=\langle u(z)\rangle$ follow the logarithmic law-of-the-wall defined as

$$
\frac{U(z)}{u_{*}}=\kappa^{-1} \ln \left(\frac{z}{z_{0}}\right)=\kappa^{-1} \ln \left(\frac{z u_{*}}{v}\right)+B-\frac{\Delta U}{u_{*}}
$$

where $u_{*}=\left\langle-u^{\prime} w^{\prime}\right\rangle^{1 / 2}$ is the friction velocity in the constant-stress layer, $\kappa$ is the von Kármán constant, $z_{0}$ is the aerodynamic roughness length, $v$ is the kinematic viscosity of air and the origin of $z$ is positioned at the mean elevation of the roughness elements. The very right-hand side of Eq. 2 is given in engineering notation, which stresses the deviation of a turbulent boundary layer over a rough wall from that over a smooth wall, and given by $U / u_{*}=\kappa^{-1} \ln \left(z u_{*} / v\right)+B$ with $B=5.0-5.5$, commonly referred to as the smoothwall intercept. $\Delta U / u_{*}$ is the roughness function and describes the shift in the mean velocity implied by the rough wall. The roughness function is equal to zero for a smooth wall and increases with aerodynamic wall roughness (Raupach et al. 1991). In Sect. 5, we make use of the roughness function $\Delta U / u_{*}$. However, both, the meteorological and engineering notation, are fully compatible. It is noted that, for simplicity, the zero-plane displacement is neglected in the formulation of the logarithmic law-of-the-wall (Eq. 2). The kinematic viscosity of air was calculated employing the empirical relation of Sutherland (e.g. White 1991) and the equation of state according to 

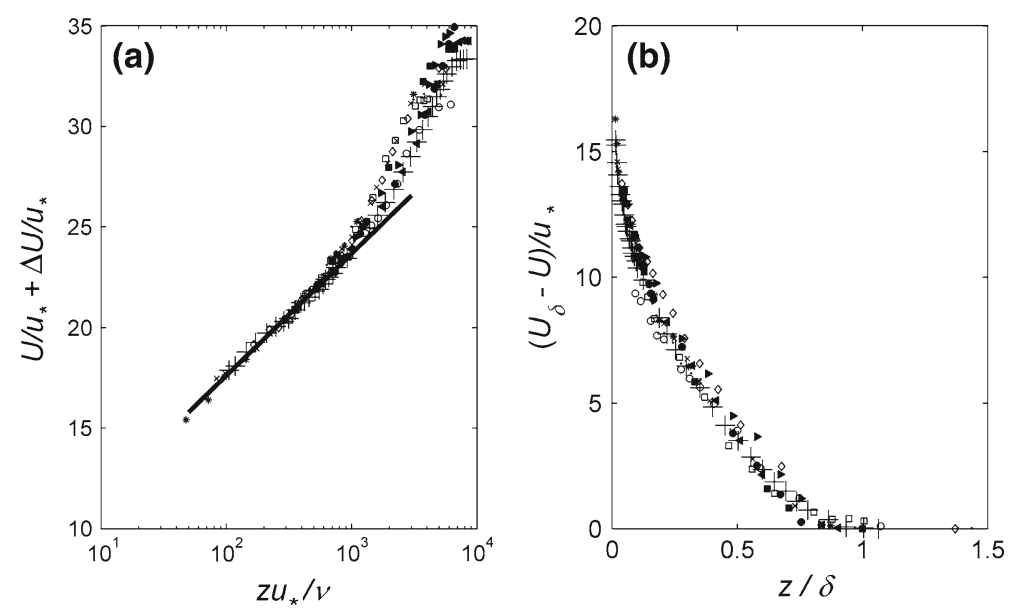

Fig. 4 Mean flow profiles for inner scaling (left) and outer scaling (right): Re $_{\theta}$ : asterisk 9800, open square 10200 , bullet 10300, times 1190, open circle 12500, open diamond 13300, filled square 19500, filled triangle right 22400, filled triangle left 24600, filled circle 26300, cross 24600 (smooth wall), black bar $\kappa^{-1} \ln \left(z^{+}\right)+5.5$

$$
v=\mu_{0}\left(\frac{T_{0}+C}{T+C}\right)\left(\frac{T}{T_{0}}\right)^{3 / 2}\left(\frac{R T}{P}\right),
$$

where $\mu_{0}$ is the reference dynamic viscosity $\left(18.27 \times 10^{-6} \mathrm{~Pa} \mathrm{~s}\right)$ at the reference temperature $T_{0}=291.15 \mathrm{~K}, C$ is the Sutherland constant $(120 \mathrm{~K}), T$ is the ambient air temperature $(K)$ and $R$ is the specific gas constant of air $\left(287.6 \mathrm{~J} \mathrm{~kg}^{-1} \mathrm{~K}^{-1}\right)$.

The aerodynamic roughness length was estimated according to the following procedure:

(1) The measured mean velocity profile was shifted upwards in the semi-logarithmic diagram (Fig. 4) by adding the roughness function $\Delta U^{+}$to approximately collapse with the theoretical smooth-wall profile given by $U^{+}=\kappa^{-1} \ln \left(z^{+}\right)+B$, with $U^{+}=U / u_{*}$, $z^{+}=z u_{*} / \nu, \kappa=0.38$ and $B=5.5$.

(2) The aerodynamic roughness length $z_{0}$ was then calculated according to

$$
z_{0}=\frac{v}{u_{*}} \exp \left\{\kappa\left(\Delta U^{+}-B\right)\right\}
$$

\section{Mean Flow and Turbulence Statistics}

Vertical profiles of first- and second-order velocity statistics are now presented to show that the flows investigated in this study can be described as canonical turbulent boundary layers. It will be shown that the profiles of the mean and fluctuating velocities obey widely the accepted paradigms of turbulent boundary-layer theory, such as the validity of the logarithmic lawof-the-wall and the outer layer hypothesis of Townsend (Townsend 1976). The agreement with such paradigms gives confidence for considering our experiments as a reliable set of data that can be employed to accurately estimate the aerodynamic roughness length of fresh snow. When plotted in standard inner scaling (i.e. using $u_{*}$ as a velocity scale and $v / u_{*}$ as a length scale) the mean velocity profiles measured over the smooth wall collapse very well with the logarithmic law-of-the-wall as given in Eq. 2 (Fig. 4a). The same applies to the snow 

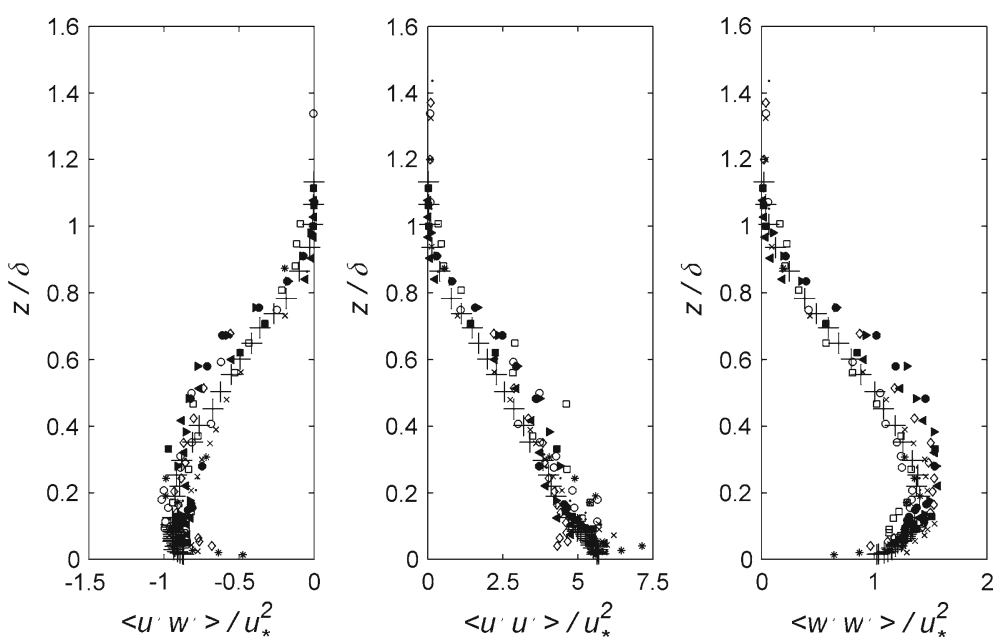

Fig. 5 Reynolds stresses. Re $e_{\theta}$ : asterisk 9800, open square 10200, bullet 10300, times 1190, open circle 12500, open diamond 13300, filled square 19500, filled triangle right 22400, filled triangle left 24600, filled circle 26300, cross 24600 (smooth wall)

data when mean velocities $U(z) / u_{*}$ are shifted by the roughness function $\Delta U^{+}$. For all the experiments, a clear logarithmic region extends up to about $z^{+}=1000$. As shown in Fig. 4b, mean velocity profiles plotted in outer scaling parameters (i.e. using $\delta$ as the scale for the vertical coordinate) collapse reasonably well within the outer-layer region (i.e. $z / \delta>0.2$ ), hence respecting Townsend's hypothesis of outer layer similarity. This observation proves that the classical turbulent boundary-layer scaling for the mean flow as generally applied to mesh, rod or sand roughness (SR) and smooth surfaces (e.g. Krogstad and Antonia 1999; DeGraaff and Eaton 2000; Flack et al. 2005) also applies to our snow surfaces.

Further agreement of the data with this hypothesis is provided by Fig. 5, which shows second-order velocity statistics normalized with outer scaling. The normalized Reynolds shear stress $\left\langle u^{\prime} w^{\prime}\right\rangle / u_{*}^{2}$, the variance of the horizontal velocity component $\left\langle u^{\prime} u^{\prime}\right\rangle / u_{*}^{2}$, and of the vertical velocity component $\left\langle w^{\prime} w^{\prime}\right\rangle / u_{*}^{2}$ collapse within the outer-layer region. It is to be noted that the outer-layer similarity is questioned for higher order statistics (e.g. Krogstad and Antonia 1999; Antonia and Krogstad 2001) and found to depend on the type of roughness. In particular, 2D roughness (e.g. transverse bars) does not always exhibit outer-layer similarity, while 3D roughness (e.g. SR) shows universal scaling (e.g. Flack et al. 2005; Schultz and Flack 2007). Though this does not represent the main goal of our investigation, Fig. 5 suggests that our results on snow roughness are in line with those obtained for 3D roughness.

\section{Estimate of the Aerodynamic Roughness Length}

The aerodynamic roughness lengths $z_{0}$ obtained from the procedure outlined in Sect. 2.4 are listed in Table 1. In general, $z_{0}$ values oscillate around a mean $\left\langle z_{0}\right\rangle=0.24 \mathrm{~mm}$ with a standard deviation $\sigma\left(z_{0}\right)=0.05 \mathrm{~mm}$. It is important to note that the boundary layers investigated in this study are in the aerodynamically rough regime and therefore, $z_{0}$ can be considered to depend solely on wall roughness. This can be observed from the results listed in Table 1. For two snow surfaces, highly sintered snow with a stable surface allowed experiments to 


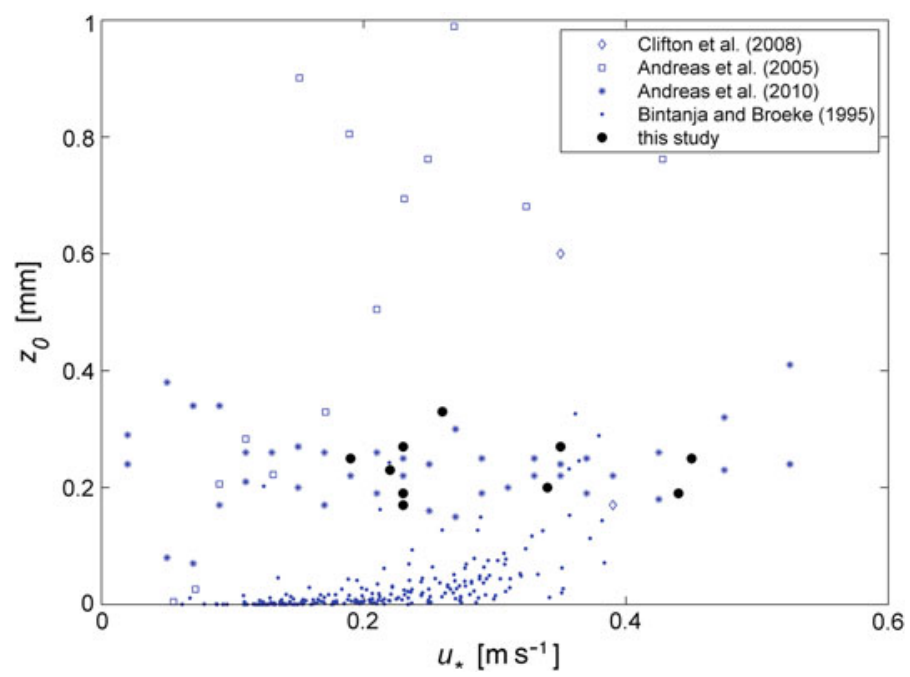

Fig. 6 Compilation of snow-surface aerodynamic roughness lengths $z_{0}$ for flat terrain largely in the absence of snow drift (data of Andreas et al. 2005, 2010 are $u_{*}$-bin averaged values)

be carried out at three (two) Reynolds numbers $R e_{\theta}$, the lowest of which being the one that was commonly reached for all the other cases. For both snow surfaces, a significant increase in $\operatorname{Re}_{\theta}$ did not correspond to a significant variation in $z_{0}$, which indeed remained basically constant. We therefore conclude that the experiments at the lowest Reynolds numbers were still in the aerodynamically rough regime. The same behaviour can be expected for all the other experiments (i.e. snow surfaces) because they were carried out at similar wall roughness and Reynolds numbers. Figure 6 reports all the $z_{0}$ values estimated in the current study, together with a compilation of data from the literature for relatively flat snow-covered terrain largely in the absence of snow drift. In the data from Clifton et al. (2008), $z_{0}$ was estimated between 0.17 and $0.60 \mathrm{~mm}$ using measurements from CTA/hot-film anemometry in the SLF cold wind tunnel but with a shorter snow fetch, about half that available in the current study. Bintanja and Van den Broeke (1995), from wind-profile measurements at two levels using cup anemometers at a flat and wind sheltered snow-covered site (their site 3) in Queen Maud Land (Antarctica), deduced $z_{0}$ values within the range of $10^{-5}-10^{-1} \mathrm{~mm}$. The bulk of their estimated roughness lengths is smaller than our values, lying between $10^{-3}$ and $10^{-1} \mathrm{~mm}$. For snow-covered sea-ice surfaces in the western Weddell Sea (Antarctica), Andreas et al. (2005) provide $z_{0}$ values lying within the range of $10^{-3} \mathrm{~mm}$. They employed single-point three-dimensional ultrasonic anemometer measurements to obtain the turbulence data. In a recent analysis of ultra sonic anemometer data recorded over snow-covered drifting sea-ice in the Arctic Beaufort gyre during the SHEABA campaign (Surface Heat Budget of the Arctic Ocean), Andreas et al. (2010) found $z_{0}$ values ranging from $10^{-2}$ to $10^{1} \mathrm{~mm}$.

Bintanja and Van den Broeke (1995) and Andreas et al. (2005) both observed increasing roughness lengths $z_{0}$ with increasing $u_{*}$ (Fig. 6). This result may be attributed to various causes: (i) the occurrence of a transitional rough-flow regime, (ii) the occurrence of snow drift for $u_{*}>0.27 \mathrm{~m} \mathrm{~s}^{-1}$ (i.e. for friction velocities exceeding the critical value of entrainment as in the study of Clifton et al. 2006) and (iii) large uncertainties in the estimation of $u_{*}$ that propagate to the computation of $z_{0}$ and generate a fictitious $z_{0}-u_{*}$ correlation (Andreas et al. 2010). Our results do not suffer from any of these problems because all the experiments were 
conducted in the aerodynamically rough regime (see Sect. 3) in the absence of snow drift, and $u_{*}$ could be estimated always accurately via the direct measurement of $\left\langle u^{\prime} w^{\prime}\right\rangle$. Indeed, our data show $z_{0}$ values lying between 0.17 and $0.33 \mathrm{~mm}$ with no apparent dependency on the friction velocity, consistently with the analysis of the SHEBA data of Andreas et al. (2010), see Fig. 6. In this study, a bulk flux algorithm was employed to estimate the logarithmic profile parameters that circumvents the problem of a fictitious correlation between $u_{*}$ and $z_{0}$. The scatter of raw data reported in Andreas et al. (2010) is, however, quite large, with the bulk spanning the range of $10^{-2}-10^{1} \mathrm{~mm}$ (not shown here). On the contrary, the small scatter in our data substantiates the fact that the boundary conditions were well controlled in all the experiments, and that any variation was induced only by the natural variability of the snow-surface roughness.

\section{Aerodynamic and Geometrical Roughness Scales}

Figure 7 shows the roughness function $\Delta U^{+}$versus the normalized roughness height $h^{+}$ for various kinds of surface roughness. The diagram is essentially a reproduction of Fig. 1 in Raupach et al. (1991) supplemented by data obtained in our wind-tunnel experiments, and provides a synopsis of geometrical and aerodynamic roughness parameterization. The dashed line for sand roughness from Prandtl and Schlichting (1934) is, for the fully rough regime $\left(h^{+}=h u_{*} / v>70\right)$, described by the relation

$$
\Delta U^{+}=\frac{1}{\kappa} \ln \left(k_{s}^{+}\right)+B-B_{r}
$$

where $k_{s}^{+}=k_{s} u_{*} / v=h^{+}$is the roughness height and $B_{r}$ is the Nikuradse roughness function $\left(B_{r}=8.5\right)$. The expression $k_{s}$ originates from engineering notation and is called the equivalent sand roughness. The use of $k_{s}$ is widespread in engineering science, and allows a comparison between different kinds of roughness. By definition, $k_{s}$ is the height of a layer of mono-disperse spherical (sand) grains packed together as densely as possible (Nikuradse 1933). To any surface roughness, an equivalent SR $k_{s}$ can be assigned that has the same implications on the mean flow as the original roughness under investigation.

The interpretation of $h$ as a roughness height deserves some explanation. In the case of square bars, $h$ is the actual geometrical height of the roughness element, while in the case of a single layer of mono-disperse most closely-packed sand grains, $h$ is equal to the diameter of the grains. However, in the case of snow, the definition of the roughness height is non-trivial. Manes et al. (2008) pointed out that the characteristic height of fresh snow roughness depends on the specific deposition process and on the occurrence (or not) of aggregation mechanisms. For snow surfaces, a meaningful geometrical roughness scale can be only derived by a statistical approach on the roughness outlines. As introduced in Sect. 2.3, we make use of the standard deviation $k_{\mathrm{rms}}=\sigma_{L}=\left[D_{2}(L) / 2\right]^{1 / 2}$ to identify a statistically based measure for the roughness height of fresh snow surfaces. As it can be seen from Fig. 7, our data points for $h^{+}=k_{\mathrm{rms}}^{+}$lie clearly above the dashed curve given by Prandtl and Schlichting (1934), see Eq. 5. The observation suggests that a proportionality factor must be applied. For instance, Allen et al. (2007) adopted the relation $k_{s}=3 k_{\text {rms }}$ for a honed pipe surface with grooves inclined to the mean flow direction. Similarly, Schultz and Flack (2007) suggest $k_{s}=3 k_{\text {rms }}$ for a sanded surface with bi-directional scratches forming a diamond-shaped pattern.

The question then is, how can $k_{\text {rms }}$ or any other geometrical scale be related with the equivalent SR $k_{s}$, or any other aerodynamic roughness scale, in the case of fresh snow? From a least-square analysis of our data, it was found that the equivalent sand roughness of 


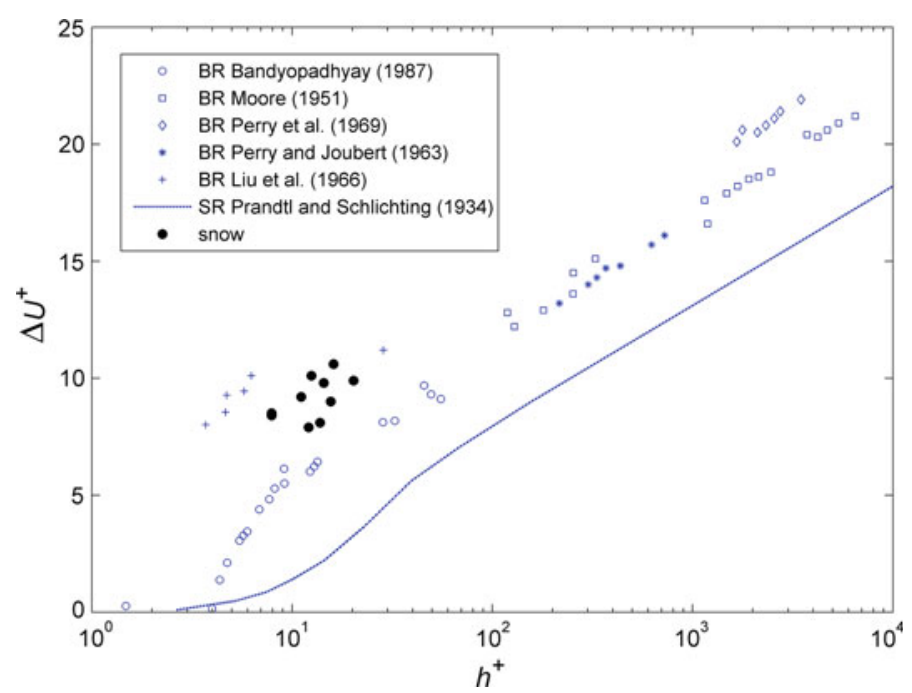

Fig. 7 Roughness function $\Delta U^{+}$versus roughness height $h^{+}$(for snow $h^{+}=k_{\mathrm{rms}}^{+}$); SR sand roughness, $B R$ bar roughness. Figure is based on Fig. 1 in Raupach et al. (1991)

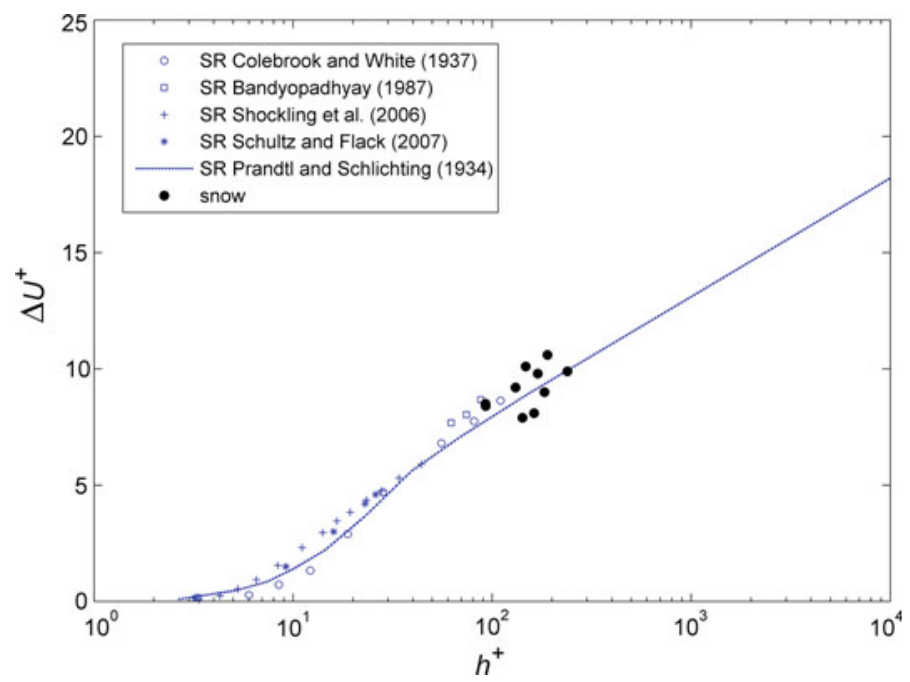

Fig. 8 Roughness function $\Delta U^{+}$versus roughness height $h^{+}\left(h^{+}=3 k_{\mathrm{rms}}^{+}\right.$for sand roughness (SR), $h^{+}=12 k_{\mathrm{rms}}^{+}$for snow). Figure is based on Fig. 1 in Raupach et al. (1991)

fresh snow is roughly 12 times larger than $k_{\mathrm{rms}}$, i.e. $k_{s}=12 k_{\mathrm{rms}}$. Figure 8 shows that when $\Delta U^{+}$is plotted versus $h^{+}=12 k_{\mathrm{rms}}^{+}$the data points lie over the relationship of Prandtl and Schlichting (1934) with reasonable scatter. Compared to sand roughness studies, the constant of proportionality for snow surfaces is significantly larger, implying that, for a given standard deviation of roughness elevations, fresh snow exerts a larger drag than that of a sanded surface. A detailed explanation of this result is provided below.

Table 2 reports how the snow equivalent SR $k_{s}$ directly estimated from $\Delta U^{+}$using Eq. 5 relates to the full set of geometrical scales defined through the structure-function analysis. 
Table 2 Length scale ratios between the snow equivalent sand roughness $k_{s}$ and geometrical roughness scales (N.B. $\left.\sigma_{L}=k_{\mathrm{rms}}\right)$

\begin{tabular}{lrrrrr}
\hline$R e_{\theta}$ & $\Delta U^{+}$ & $k_{s} / l$ & $k_{s} / \sigma_{l}$ & $k_{s} / L$ & $k_{s} / k_{\mathrm{rms}}$ \\
\hline 9800 & 8.4 & 24.5 & 40.2 & 2.0 & 15.2 \\
10200 & 8.5 & 21.8 & 36.1 & 1.4 & 15.9 \\
10300 & 7.9 & 12.1 & 25.1 & 0.9 & 8.1 \\
11900 & 8.1 & 9.9 & 18.1 & 0.9 & 7.7 \\
12500 & 9.9 & 34.5 & 56.5 & 2.1 & 11.1 \\
13300 & 9.0 & 20.0 & 41.5 & 0.8 & 9.9 \\
19500 & 9.2 & 11.5 & 20.4 & 3.1 & 15.1 \\
22400 & 10.1 & 28.2 & 46.2 & 1.7 & 19.6 \\
24600 & 9.8 & 9.0 & 14.7 & 3.1 & 15.0 \\
26300 & 10.6 & 18.2 & 27.1 & 1.6 & 18.8 \\
\hline
\end{tabular}

As introduced in Sect. 2.3, the fresh snow roughness investigated in this study is characterized by essentially two roughness scales: one corresponding to the crystal diameter and another associated with roughness elements emerging from the dynamics of the deposition process (Manes et al. 2008). Such roughness elements are significantly larger than the crystal diameter and, therefore, dominate momentum transfer at the snow-air interface. As shown in Table 2, the characteristic horizontal length scale (i.e. $L$ ) of these roughness elements is much larger than their vertical length scale (i.e. $k_{\text {rms }}$ ) and, therefore, they appear as elongated bumps. Such elongated roughness elements exert a higher flow resistance (i.e. larger $k_{s}$ ) than a sanded surface with equal $k_{\mathrm{rms}}$. Indeed, sanded surfaces are characterized by mono-disperse regular roughness elements deployed with the tightest packing that, using the jargon developed by Morris (1955) for square bar roughness, promotes the development of a skimming flow. Fresh snow roughness emerging from ballistic deposition processes is instead characterized by elongated bumps that are more likely to develop a wake interference flow, which is notoriously characterized by larger drag coefficients than a skimming flow (Schlichting and Gersten 2003).

\section{Conclusions}

In this article, velocity measurements in a zero pressure gradient turbulent boundary layer obtained in a cold wind tunnel over fresh snow surfaces are presented. Mean and fluctuating velocity profiles were found to obey the typical scaling of sand-type rough walls. The correct scaling of mean and turbulence statistics allows a robust estimate of the friction velocity and thus of an aerodynamic length scale. We can therefore propose a mean value for the aerodynamic roughness length of $z_{0}=0.24 \mathrm{~mm}$ with a standard deviation of $\sigma\left(z_{0}\right)=0.05 \mathrm{~mm}$ and a range between 0.17 and $0.33 \mathrm{~mm}$. This estimate is meant to be a representative for flat fresh snow surfaces in the absence of drift, and of additional effects such as complex terrain and surface features like snow ripples or sastrugi.

Based on the analysis of snow-surface characteristics, we further propose a relationship between the snow equivalent sand roughness and the geometrical surface roughness $k_{s}=12 k_{\mathrm{rms}}$ for fresh snow, analogous to the $k_{s}=3 k_{\mathrm{rms}}$ relationship found for honed or sanded roughness (e.g. Allen et al. 2007; Schultz and Flack 2007). The higher constant of 
proportionality is consistent with the presence of elongated roughness elements on the snow surface as predicted by ballistic deposition models (Manes et al. 2008).

We point out that in our set-up, we were constrained by a fresh snowpack not higher than $0.15 \mathrm{~m}$. Heavy snowfalls may lead to thicker snowpacks characterized by larger roughness scales on the snow surface that may eventually have an impact on the aerodynamic roughness length. We also point out that our study focuses on fresh snow roughness emerging from snowfalls that mimic ballistic deposition processes. However, different environmental conditions may generate snowfalls governed by different deposition dynamics and ultimately to roughness characterized by a different scaling behaviour. Therefore, further studies must be devoted to the estimate of the aerodynamic roughness length of fresh snow in more complex and diverse environmental conditions.

Acknowledgements The study and wind-tunnel facility were partially funded by the Swiss National Science Foundation and by the Vontobel foundation (Benjamin Walter). Technical support from the SLF workshop is acknowledged. The authors wish to thank Frank Graf, Andy Clifton and Katherine Leonard from the WSL Institute for Snow and Avalanche Research SLF for many helpful discussions and Michael Raupach from CSIRO for kindly providing the data reported in Figs. 7 and 8.

\section{References}

Allen JJ, Shockling MA, Kunkel GJ, Smits AJ (2007) Turbulent flow in smooth and rough pipes. Philos Trans Roy Soc Lond A 365:699-714

Andreas EL, Claffey KJ (1995) Air-ice drag coefficients in the western Weddell Sea. 1. Values deduced from profile measurements. J Geophys Res 100:4821-4831

Andreas EL, Jordan R, Makshtas A (2005) Parameterizing turbulent exchange over sea ice: The Ice Station Weddell results. Boundary-Layer Meteorol 114:439-460

Andreas EL, Persson POG, Jordan RE, Horst TW, Guest PS, Grachev AA, Fairall CW (2010) Parameterizing turbulent exchange over sea ice in winter. J Hydrometeorol 11:87-104

Antonia R, Krogstad P (2001) Turbulence structure in boundary layers over different types of surface roughness. Fluid Dyn Res 28:139-157

Barabási A, Stanley H (1995) Fractal concepts in surface growth. Cambridge University Press, Cambridge, $386 \mathrm{pp}$

Bartlett S, Lehning M (2011) Heat transfer by ventilation in a homogeneous snowpack. Water Resour Res (in press)

Bintanja R, Van den Broeke M (1995) Momentum and scalar transfer-coefficients over aerodynamically smooth Antarctic surfaces. Boundary-Layer Meteorol 74:89-111

Calanca P (2001) A note on the roughness length for temperature over melting snow and ice. Q J R Meteorol Soc 127:255-260

Chamberlain A (1983) Roughness length of sea, sand, and snow. Boundary-Layer Meteorol 25:405-409

Charnock H (1955) Wind stress on a water surface. Q J R Meteorol Soc 81:639-640

Clifton A, Lehning M (2008) Improvement and validation of a snow saltation model using wind tunnel measurements. Earth Surf Process Landf 33:2156-2173

Clifton A, Ruedi JD, Lehning M (2006) Snow saltation threshold measurements in a drifting-snow wind tunnel. J Glaciol 52:585-596

Clifton A, Manes C, Rueedi JD, Guala M, Lehning M (2008) On shear-driven ventilation of snow. BoundaryLayer Meteorol 126:249-261

DeGraaff D, Eaton J (2000) Reynolds-number scaling of the flat-plate turbulent boundary layer. J Fluid Mech 422:319-346

Doorschot J, Raderschall N, Lehning M (2001) Measurements and one-dimensional model calculations of snow transport over a mountain ridge. Ann Glaciol 32:153-158

Doorschot J, Lehning M, Vrouwe A (2004) Field measurements of snow-drift threshold and mass fluxes, and related model simulations. Boundary-Layer Meteorol 113:347-368

Flack K, Schultz M, Shapiro T (2005) Experimental support for Townsend's Reynolds number similarity hypothesis on rough walls. Phys Fluids 17:035102-035102-9

Foken T (2008) Micrometeorology. Springer, Berlin, 308 pp 
Guala M, Hommema S, Adrian R (2006) Large-scale and very-large-scale motions in turbulent pipe flow. J Fluid Mech 554:521-542

Guala M, Manes C, Clifton A, Lehning M (2008) On the saltation of fresh snow in a wind tunnel: profile characterization and single particle statistics. J Geophys Res 113:F03024

Guala M, Metzger M, McKeon BJ (2011) Interactions within the turbulent boundary layer at high Reynolds number. J Fluid Mech 666:573-604

Herzfeld UC, Mayer H, Caine N, Losleben M, Erbrecht T (2003) Morphogenesis of typical winter and summer snow surface patterns in a continental alpine environment. Hydrol Process 17:619-649

Inoue J (1989) Surface drag over the snow surface of the Antarctic plateau. 1. Factors controlling surface drag over the katabatic wind region. J Geophys Res 94:2207-2217

Jackson BS, Carroll JJ (1978) Aerodynamic roughness as a function of wind direction over asymmetric surface elements. Boundary-Layer Meteorol 14:323-330

Kaimal JC, Finnigan JJ (1994) Atmospheric boundary layer flows: their structure and measurement. Oxford University Press, New York, 304 pp

Krogstad P, Antonia R (1999) Surface roughness effects in turbulent boundary layers. Exp Fluids 27:450-460

Lehning M, Fierz C (2008) Assessment of snow transport in avalanche terrain. Cold Reg Sci Technol 51: 240-252

Lehning M, Lowe H, Ryser M, Raderschall N (2008) Inhomogeneous precipitation distribution and snow transport in steep terrain. Water Resour Res 44:W07404

Leonard K (2009) Antarctic snow drift processes. Dissertation, Columbia University

Lowe H, Egli L, Bartlett S, Guala M, Manes C (2007) On the evolution of the snow surface during snowfall. Geophys Res Lett 34:L21507

Manes C, Guala M, Lowe H, Bartlett S, Egli L, Lehning M (2008) Statistical properties of fresh snow roughness. Water Resour Res 44:W11407

Morris HM (1955) Flow in rough conduits. Trans ASCE 120:373-410

Nikuradse J (1933) Laws of flow in rough pipes. Reprint in National Advisory Committee for Aeronautics (NACA), Technical memorandum 1292 (1960), 63 pp

Orlandi P, Leonardi S (2008) Direct numerical simulation of three-dimensional turbulent rough channels: parameterization and flow physics. J Fluid Mech 606:399-415

Owen PR (1964) Saltation of uniform grains in air. J Fluid Mech 20:225-242

Pinzer B, Schneebeli M (2009) Snow metamorphism under alternating temperature gradients: morphology and recrystallization in surface snow. Geophys Res Lett 36:L23503

Poggi A (1977) Heat balance in ablation area of Ampere glacier (Kerguelen Islands). J Appl Meteorol 16: 48-55

Pomeroy J, Gray D (1990) Saltation of snow. Water Resour Res 26:1583-1594

Prandtl L, Schlichting H (1934) Das Widerstandsgesetz rauher Platten. Werft Reed Hafen 15:1-4

Raupach M (1991) Saltation layers, vegetation canopies and roughness lengths. Acta Mech Suppl 2:83-96

Raupach M, Antonia R, Rajagopalan S (1991) Rough wall turbulent boundary layers. Appl Mech Rev 44:1-25

Schlichting H, Gersten K (2008) Boundary layer theory. Springer, Berlin, 801 pp

Schultz MP, Flack KA (2007) The rough-wall turbulent boundary layer from the hydraulically smooth to the fully rough regime. J Fluid Mech 580:381-405

Stoessel F, Guala M, Fierz C, Manes C, Lehning M (2010) Micrometeorological and morphological observations of surface hoar dynamics on a mountain snow cover. Water Resour Res 46:W04511

Townsend A (1976) The structure of turbulent shear flow. Cambridge University Press, U.K., 944 pp

White FM (1991) Viscous fluid flow. McGraw-Hill, New York, 614 pp 